\title{
Transient State Modelling and Experimental Investigation of the Thermal Behavior of a Vapor Compression System
}

\author{
Conrad Sanama $(\mathbb{D})$ and Xiaohua Xia $(\mathbb{D}$ \\ Centre of New Energy Systems, Department of Electrical, Electronic and Computer Engineering, University of Pretoria, \\ Private Box X20, Hatfield, Pretoria 0028, South Africa \\ Correspondence should be addressed to Conrad Sanama; u12088987@tuks.co.za and Xiaohua Xia; xiaohua.xia@up.ac.za
}

Received 26 March 2021; Accepted 21 May 2021; Published 28 July 2021

Academic Editor: Jianguo Wang

Copyright (C) 2021 Conrad Sanama and Xiaohua Xia. This is an open access article distributed under the Creative Commons Attribution License, which permits unrestricted use, distribution, and reproduction in any medium, provided the original work is properly cited.

\begin{abstract}
The main objective of this work is to establish a detailed modelling technique to predict the refrigerant conditions such as pressure and enthalpy of a VC system. The transient state modelling techniques suggested in many research works are usually not easy to reproduce due to lack of detailed methodology and the multitude of analytical or computational schemes that could not be assessed objectively. This work has addressed this issue by introducing a modelling method developed from conservation equations of mass and energy represented with Navier-Stokes equations. A finite volume scheme has been used to discretize the governing equations along the heat exchanger models. Transient state modelling matrices have been established after dividing the condenser as well as the evaporator into 3 and $n$ control volumes. The model validation with experiments was satisfactory. The model outputs such as the refrigerant pressure across the condenser and evaporator are in agreement with experiments. The proposed modelling technique could be adopted to predict optimal parameters during start-up. The modelling results could be used to design VC systems with optimal performance.
\end{abstract}

\section{Introduction}

Critical processes could be identified through modelling in order to draw key design requirements [1]. Modelling of vapor compression (VC) systems consists of investigating their variation so that optimal parameters' values could be determined.

The objective of this work is to use mathematical and experimental approaches to offer an accurate predictive model of the parameters of VC systems so that optimal values could be determined to achieve optimal design under dynamics conditions.

Early modelling of transient state of heat exchangers was performed by Wedekind et al. [2] using a mean void fraction model to convert two-phase flow in heat exchangers into the lumped parameter model in order to obtain simple and closed solution forms. Transient state modelling of window air conditioner (AC) was presented by Dhar and Soedel [3] using a moving boundary method for refrigerant flow in heat exchangers. Two-phase refrigerant in heat exchangers was assumed to undergo mass transfer internally and heat transfer externally. Important transient responses of the system were predicted with accuracy despite the model simplicity based on quasi-steady state formulation. The model validation with experiments was not provided for this work [4].

Chi and Didion [4] made an improvement in transient state modelling. Transient equations of continuity, momentum, and energy were used to formulate the lumped parameter models of the components. Time-dependent model equations of all components except the expansion valve were derived and solved numerically with the Euler method. The predicted refrigerant outlet conditions at each component were converging with test data for 6 minutes of starting time. The early distributed parameter model of heat exchangers was proposed by $[5,6]$ to analytically represent the dynamic behavior of VC systems. The model of heat exchangers was decomposed into 3 elements, namely, the 
refrigerant, secondary fluid, and heat exchanger wall. The transient energy interaction of the 3 elements was represented by a set of one-dimensional and time-dependent partial differential equations (PDE's) derived from the conservation of energy and mass. The PDE's solution was determined by dividing the heat exchangers in small control volumes to perform spatial and temporal integrations satisfying the conservation equations of each element of the model for any grid space and step size. The work in $[5,6]$ led to weak predictions of mass distribution by assuming uniform velocity field in heat exchangers. Improvement was proposed by MacArthur and Grald [7] who predicted the pressure response with coupled mass and energy balance.

Nyers and Stoyan [8] used the distributed parameter model to investigate the transient behavior of an evaporator. The refrigerant in the evaporator was modelled as homogeneous liquid and gas mixture. The conservation equations of the refrigerant led to PDE's derived under stated assumptions. Finite difference for PDE's discretization was used and Gaussian elimination was adopted for solution tracking. Parameters such as refrigerant pressure and temperature were predicted with the distributed model; however, numerical results were not validated with the experiments. Detailed transient state modelling was presented by [9] using a lumped parameter model to investigate the liquid, two-phase, and vapor zones in heat exchangers. The conservation law was used to derive the governing equations of the refrigerant within each zone. The governing equations were integrated within each zone to determine 12 parameters defining the lumped model. Pettit et al. [10] used the resulting model to establish a simulation model of an evaporator running under wide operating conditions. Moving boundary formulation was adopted to simulate the refrigerant flow as it transited through the liquid, two-phase, and vapor zones. Four regions in the evaporator were considered for simulation and the effects of moving a region in or out of the evaporator were expressed by the set of differential equations. The modelling method was not integrated within a complete VC system; however, it displayed important insights for transient state modelling of heat exchangers.

McKinley and Alleyne [11] developed an advanced dynamic and nonlinear switched model of heat exchangers using the moving boundary approach. The model was derived from the conservation of mass and energy. To address the singularity aspect, making the moving boundary technique fall short under certain conditions, particular attention was drawn on the algorithm for wall temperature zoning and for switch of heat exchangers' configuration [11]. The model's robustness was demonstrated with various tests applicable to chiller systems. The robustness was improved for different operating conditions and the prediction was more accurate. Li and Alleyne [12] adopted the aforementioned model to implement a dynamic model of the system with on-off cycling in Matlab-Simulink that was successfully validated with the experiments. The results revealed the potential of switched heat exchanger modelling for improvement of the control system design [12]. Zhang et al. [13] numerically analyzed the transient behavior of the components of VC systems. Transient, steady, and pressure drop forms of momentum equations were adopted for comparison at the system level [13]. The results obtained using the transient form of momentum equations was more satisfactory at the system level.

Link and Deschamps [14] have investigated numerical modelling of transient effects during compressor start-up. The model considered a system in thermal equilibrium due to a long-time scale with regards to thermal behavior within the compressor. The results showed that transient effects during start-up affect the compressor's dynamic at its suction and discharge lines [14]. Rasmussen [15] reviewed the literatures for transient state modelling. The modelling techniques were categorized in model- and data-based schemes. The model-based approach was developed from first principles and was divided in 3 subcategories, namely, the finite control volume, moving boundary, and lumped parameters methods. The model-based approach required validation with the experiments and was later on detailed in [16] using finite volume and moving boundary methods to discuss benefits and limitations of both schemes. Satyavada and Baldi [17] used a finite volume scheme to develop a dynamic model of a condensing boiler which could avoid static nonlinear efficiency curves whilst accounting for a transient dry and wet heat exchange proportion. This model was adopted by [18] for monitoring purpose of the energy efficiency of a water heater fueled by gas.

Pangborn [19] used finite volume and moving boundary approaches to represent the condenser and evaporator models of a VC system. The heat exchanger models were validated with the experiments. The outputs were predicted with more accuracy at high humidity conditions. Pangborn et al. [20] also compared finite volume and moving boundary schemes, and the conclusion showed that both approaches could achieve similar level of accuracy. The finite volume scheme appeared more flexible for modelling of various heat exchangers' configuration, whilst the moving boundary scheme displayed the fastest simulation speed [20].

Bagheri [21], using transient state modelling, developed a thermal simulation of the VC system. The results were in agreement with field and experimental data. Diniz et al. [22] presented a simulation of unsteady behavior of a refrigerating VC system in order to predict its performance. The system was subject to on-off cycling of the reciprocating compressor [22]. The compressor model was presented with an approach similar to [23] using transient and thermal submodels. Other component's models were established from the conservation equations of mass and energy. The results were validated with the experiments, and under carefully prescribed boundary conditions, the system's performances could accurately be predicted.

The models found in the literature do not usually disclose detailed steps of solution tracking, thus making them difficult to reproduce and adopt with other similar problems. This work intends to address this problem by using existing modelling equations to provide a very detailed scheme whose results are validated with the experiments. This work is based on the application of existing mathematical 
techniques [24] to evaluate the optimal parameter values of VC systems.

\section{Transient Modelling of the VC System}

Figure 1 describes a conventional VC system with its junctions.

The compressor is used to raise the pressure of the circulating refrigerant, while the condenser rejects, to the surrounding environment, an amount of heat associated to the energy absorbed by the refrigerant during the cycle. An expansion valve is located downstream of the condenser in order to regulate the refrigerant flow prior to entering the evaporator whose function is to absorb heat from the surrounding environment to provide cooling effect. The junctions are used as interconnection between the components.

2.1. Compressor and Expansion Valve Modelling. Assuming adiabatic compression, the outlet condition and refrigerant mass flow rate at the compressor can be defined as follows:

$$
\begin{aligned}
h_{\text {comp }, \text { out }} & =h_{\text {comp,in }}+\frac{h_{\text {isen,out }}-h_{\text {comp,in }}}{\eta_{\text {isen }}}, \\
m_{\text {comp }} & =\eta_{\text {vol }} \rho_{\text {comp, in }} D_{v} \frac{\mathrm{RPM}_{\text {comp }}}{60} .
\end{aligned}
$$

The refrigerant mass flow rate at the thermostatic expansion valve can be derived as follows:

$$
m_{t x v}=C_{t x v}\left(T_{S h, \text { operating }}-T_{S h, \text { static }}\right) \sqrt{\rho_{t x v, \text { in }}\left(P_{t x v, \text { in }}-P_{t x v, \text { out }}\right)} .
$$

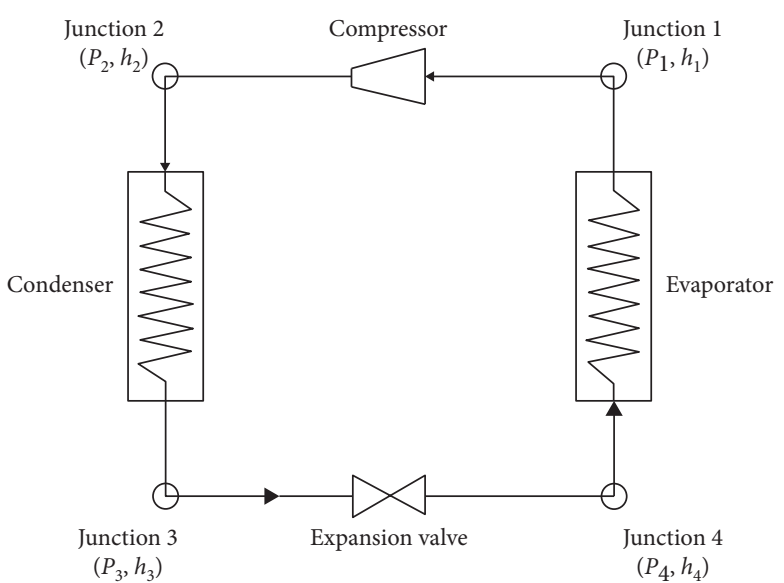

FIGURE 1: Junction of a conventional vapor compression system [25].

2.2. Condenser Modelling. Neglecting the refrigerant pressure loss, the equations for conservation of mass and energy of the refrigerant within the condenser can be written as follows:

$$
\begin{array}{r}
\frac{\partial \rho}{\partial t}+\frac{\partial(\rho u)}{\partial x}=0 \\
\frac{\partial(\rho h)}{\partial t}+\frac{\partial(\rho u h)}{\partial x}+\delta Q_{\text {ref }}=0 .
\end{array}
$$

The conservation equations could be discretized with a finite volume scheme across each control volume of the condenser represented in Figure 2.

Considering the $i^{\text {th }}$ control volume in Figure 2 to be bounded by the inlet and outlet refrigerant conditions, equations (4) and (5) could be discretized as follows:

$$
\begin{array}{r}
\frac{\partial(\rho V)_{i}}{\partial t}-\left(m_{\text {cond,ref }}\right)_{\text {in }}+\left(m_{\text {cond,ref }}\right)_{\text {out }}=0 \\
\frac{\partial(\rho h V)_{i}}{\partial t}-\left(m_{\text {cond,ref }}\right)_{\text {in }} h_{\text {cond,in }}+\left(m_{\text {cond,ref }}\right)_{\text {out }} h_{\text {cond,out }}+Q_{\text {ref }, i}=0 .
\end{array}
$$

Equations (6) and (7) can be arranged by decomposing the derivative of $\rho=f(P, h)$ with the chain rule for partial derivative as follows:

$$
\begin{aligned}
& V_{i}\left[\left.\frac{\partial \rho_{i}}{\partial P}\right|_{h, i} \frac{\mathrm{d} P_{\text {cond }}}{\mathrm{d} t}+\left.\frac{\partial \rho_{i}}{\partial h_{i}}\right|_{P} \frac{\mathrm{d} h_{i}}{\mathrm{~d} t}\right]=\left(m_{\text {cond,ref }}\right)_{\text {in }}-\left(m_{\text {cond,ref }}\right)_{\text {out' }}, \\
& V_{i}\left[\left(\left.h_{i} \frac{\partial \rho_{i}}{\partial P}\right|_{h, i}-1\right) \frac{\mathrm{d} P_{\text {cond }}}{\mathrm{d} t}+\left(\left.h_{i} \frac{\partial \rho_{i}}{\partial P}\right|_{P}+\rho_{i}\right) \frac{\mathrm{d} h_{i}}{\mathrm{~d} t}\right]=\left(m_{\text {cond,ref }}\right)_{\text {in }} h_{\text {cond,in }}-\left(m_{\text {cond,ref }}\right)_{\text {out }} h_{\text {cond,out }} \\
& \text { - } Q_{\text {ref }, i} \text {. }
\end{aligned}
$$




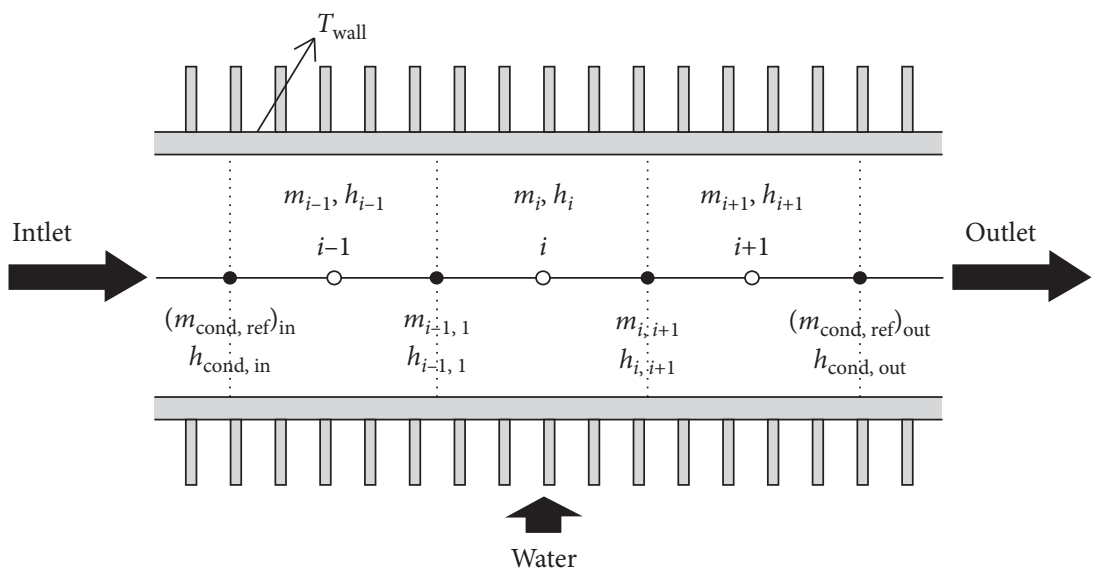

Figure 2: Control volumes of the condenser.

The rate of heat rejection from the refrigerant to the condenser pipe wall within the $i^{\text {th }}$ control volume is given as follows:

$$
Q_{\mathrm{ref}, i}=\alpha_{i} \frac{A_{i}}{N_{\text {cells }}}\left(T_{i}-T_{\text {wall }, i}\right) .
$$

In transient operation, the temperature of the condenser pipe wall changes with time, and this change can be determined as follows:

$$
\begin{aligned}
\frac{(\mathrm{MC})_{\text {cond }}}{N_{\text {cells }}} \frac{\mathrm{d} T_{\text {wall }, i}}{\mathrm{~d} t} & =Q_{\text {ref }, i}-Q_{\text {water }, i}, \\
Q_{\text {water }, i} & =U_{\text {cond,water }} \frac{A_{o, \text { eff }}}{N_{\text {cells }}}\left(T_{\text {wall }, i}-T_{\text {water,in }}\right), \\
A_{\text {cond,eff }} & =A_{\text {cond,tube }}+\eta_{\text {cond,fin }} A_{\text {cond,fin }} .
\end{aligned}
$$

\section{Discretization of the Modelling Equations of the Condenser}

Equations (4) and (5) within the condenser model (Figure 2) could be discretized within the $(i-1)^{\text {th }}, i^{\text {th }}$, and $(i+1)^{\text {th }}$ control volumes to obtain the following set of equations:

$$
\left\{\begin{array}{l}
\left(m_{\text {cond,ref }}\right)_{\text {in }} h_{i-1}-m_{i-1, i} h_{i-1}-V_{i-1} \frac{\mathrm{d} P_{\text {cond }}}{\mathrm{d} t}+V_{i-1} \rho_{i-1} \frac{\mathrm{d} h_{i-1}}{\mathrm{~d} t}+m_{i-1, i} h_{i-1, i}=\left(m_{\text {cond,ref }}\right)_{\text {in }} h_{\text {cond,in }}-\alpha_{i-1} \frac{A_{i-1}}{N_{\text {cells }}}\left(T_{i-1}-T_{\text {wall }, i-1}\right), \\
m_{i-1, i} h_{i}-m_{i, i+1} h_{i}-V_{i} \frac{\mathrm{d} P_{\text {cond }}}{\mathrm{d} t}+V_{i} \rho_{i} \frac{\mathrm{d} h_{i}}{\mathrm{~d} t}-m_{i-1, i} h_{i-1, i}+m_{i, i+1} h_{i, i+1}=-\alpha_{i} \frac{A_{i}}{N_{\text {cells }}}\left(T_{i}-T_{\text {wall }, i}\right), \\
m_{i, i+1} h_{i+1}-\left(m_{\text {cond,ref }}\right)_{\text {out }} h_{i+1}-V_{i+1} \frac{\mathrm{d} P_{\text {cond }}}{\mathrm{d} t}+V_{i+1} \rho_{i+1} \frac{\mathrm{d} h_{i+1}}{\mathrm{~d} t}+m_{i, i+1} h_{i, i+1}=-\left(m_{\text {cond,ref }}\right)_{\text {out }} h_{\text {cond,out }}-\alpha_{i+1} \frac{A_{i+1}}{N_{\text {cells }}}\left(T_{i+1}-T_{\text {wall }, i+1}\right) .
\end{array}\right.
$$

Equation (11) could be arranged as follows: 


$$
\left\{\begin{array}{l}
\left(m_{\text {cond,ref }}\right)_{\text {in }} h_{i-1}-V_{i-1} \frac{\mathrm{d} P_{\text {cond }}}{\mathrm{d} t}+V_{i-1} \rho_{i-1} \frac{\mathrm{d} h_{i-1}}{\mathrm{~d} t}+m_{i-1, i}\left(h_{i-1, i}-h_{i-1}\right)=\left(m_{\text {cond,ref }}\right)_{\text {in }} h_{\text {cond,in }}-\alpha_{i-1} \frac{A_{i-1}}{N_{\text {cells }}}\left(T_{i-1}-T_{\text {wall, } i-1}\right), \\
m_{i-1, i}\left(h_{i}-h_{i-1, i}\right)-V_{i} \frac{\mathrm{d} P_{\text {cond }}}{\mathrm{d} t}+V_{i} \rho_{i} \frac{\mathrm{d} h_{i}}{\mathrm{~d} t}+m_{i, i+1}\left(h_{i, i+1}-h_{i}\right)=-\alpha_{i} \frac{A_{i}}{N_{\text {cells }}}\left(T_{i}-T_{\text {wall }, i}\right), \\
m_{i, i+1}\left(h_{i+1}-h_{i, i+1}\right)-\left(m_{\text {cond,ref }}\right)_{\text {out }} h_{i+1}-V_{i+1} \frac{\mathrm{d} P_{\text {cond }}}{\mathrm{d} t}+V_{i+1} \rho_{i+1} \frac{\mathrm{d} h_{i+1}}{\mathrm{~d} t}=-\left(m_{\text {cond,ref }}\right)_{\text {out }} h_{\text {cond,out }}-\alpha_{i+1} \frac{A_{i+1}}{N_{\text {cells }}}\left(T_{i+1}-T_{\text {wall }, i+1}\right) .
\end{array}\right.
$$

Assuming the enthalpy variation from a nodal point to accounted in transient state modelling, equation (12) could an intermediary point (Figure 2) as small enough to be

$$
\left\{\begin{array}{l}
\left(m_{\text {cond,ref }}\right)_{\text {in }} h_{i-1}-V_{i-1} \frac{\mathrm{d} P_{\text {cond }}}{\mathrm{d} t}+V_{i-1} \rho_{i-1} \frac{\mathrm{d} h_{i-1}}{\mathrm{~d} t}=\left(m_{\text {cond,ref }}\right)_{\text {in }} h_{\text {cond,in }}-\alpha_{i-1} \frac{A_{i-1}}{N_{\text {cells }}}\left(T_{i-1}-T_{\text {wall }, i-1}\right), \\
-V_{i} \frac{\mathrm{d} P_{\text {cond }}}{\mathrm{d} t}+V_{i} \rho_{i} \frac{\mathrm{d} h_{i}}{\mathrm{~d} t}=-\alpha_{i} \frac{A_{i}}{N_{\text {cells }}}\left(T_{i}-T_{\text {wall }, i}\right), \\
-\left(m_{\text {cond,ref }}\right)_{\text {out }} h_{i+1}-V_{i+1} \frac{\mathrm{d} P_{\text {cond }}}{\mathrm{d} t}+V_{i+1} \rho_{i+1} \frac{\mathrm{d} h_{i+1}}{\mathrm{~d} t}=-\left(m_{\text {cond,ref }}\right)_{\text {out }} h_{\text {cond,out }}-\alpha_{i+1} \frac{A_{i+1}}{N_{\text {cells }}}\left(T_{i+1}-T_{\text {wall }, i+1}\right) .
\end{array}\right.
$$

The transient terms in equation (13) could be approximated with their initial and final conditions of the pressure, and this yields to

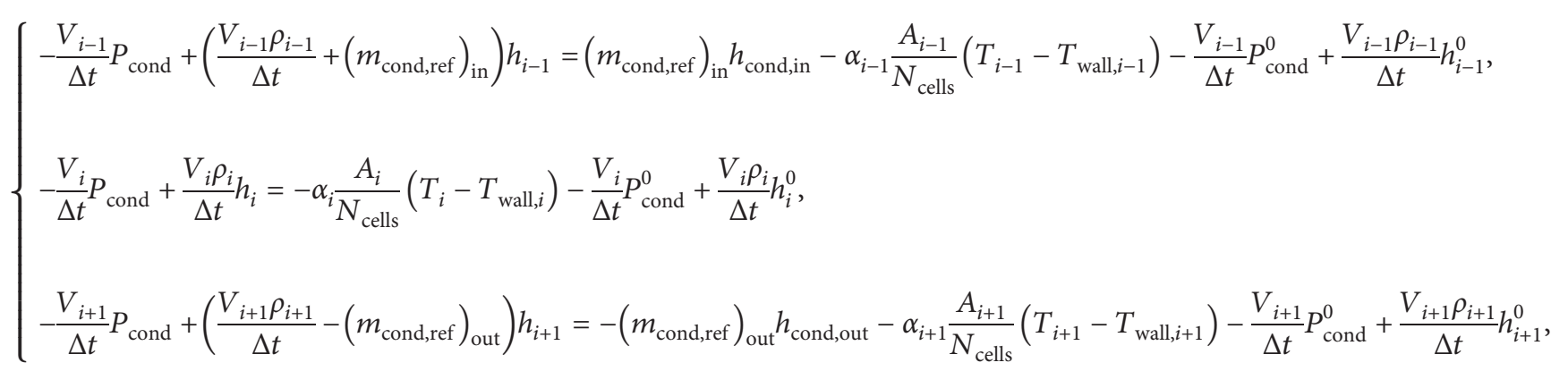

$$
\Delta t=t-t^{0}
$$

The enthalpy at the central node of the condenser model could be approximated using a central difference scheme and expressed as follows:

$$
h_{i}=\frac{h_{i-1}+h_{i+1}}{2}
$$


By inserting equations (16) into (14), the system of equations to be solved for transient state modelling could be written as follows:

$$
\left\{\begin{array}{l}
-\frac{V_{i-1}}{\Delta t} P_{\text {cond }}+\left(\frac{V_{i-1} \rho_{i-1}}{\Delta t}+\left(m_{\text {cond,ref }}\right)_{\text {in }}\right) h_{i-1}=\left(m_{\text {cond,ref }}\right)_{\text {in }} h_{\text {cond,in }}-\alpha_{i-1} \frac{A_{i-1}}{N_{\text {cells }}}\left(T_{i-1}-T_{\text {wall }, i-1}\right)-\frac{V_{i-1}}{\Delta t} P_{\text {cond }}^{0}+\frac{V_{i-1} \rho_{i-1}}{\Delta t} h_{i-1}^{0}, \\
-\frac{V_{i}}{\Delta t} P_{\text {cond }}+\frac{1}{2} \frac{V_{i} \rho_{i}}{\Delta t} h_{i-1}+\frac{1}{2} \frac{V_{i} \rho_{i}}{\Delta t} h_{i+1}=-\alpha_{i} \frac{A_{i}}{N_{\text {cells }}}\left(T_{i}-T_{\text {wall, },}\right)-\frac{V_{i}}{\Delta t} P_{\text {cond }}^{0}+\frac{V_{i} \rho_{i}}{\Delta t} h_{i}^{0}, \\
-\frac{V_{i+1}}{\Delta t} P_{\text {cond }}+\left(\frac{V_{i+1} \rho_{i+1}}{\Delta t}-\left(m_{\text {cond,ref }}\right)_{\text {out }}\right) h_{i+1}=-\left(m_{\text {cond,ref }}\right)_{\text {out }} h_{\text {cond,out }}-\alpha_{i+1} \frac{A_{i+1}}{N_{\text {cells }}}\left(T_{i+1}-T_{\text {wall }, i+1}\right)-\frac{V_{i+1}}{\Delta t} P_{\text {cond }}^{0}+\frac{V_{i+1} \rho_{i+1}}{\Delta t} h_{i+1}^{0} .
\end{array}\right.
$$

Equation (17) could be represented in the matrix form as follows:

$$
\begin{aligned}
& {\left[\begin{array}{ccc}
-\frac{V_{i-1}}{\Delta t} \frac{V_{i-1} \rho_{i-1}}{\Delta t}+\left(m_{\text {cond,ref }}\right)_{\text {in }} & 0 \\
-\frac{V_{i}}{\Delta t} & \frac{1}{2} \frac{V_{i} \rho_{i}}{\Delta t} & \frac{1}{2} \frac{V_{i} \rho_{i}}{\Delta t} \\
-\frac{V_{i+1}}{\Delta t} & 0 & \frac{V_{i+1} \rho_{i+1}}{\Delta t}-\left(m_{\text {cond,ref }}\right)_{\text {out }}
\end{array}\right]\left[\begin{array}{l}
P_{\text {cond }} \\
h_{i-1} \\
h_{i+1}
\end{array}\right]} \\
& =\left[\begin{array}{l}
\left(m_{\text {cond,ref }}\right)_{\text {in }} h_{\text {cond,in }}-\alpha_{i-1} \frac{A_{i-1}}{N_{\text {cells }}}\left(T_{i-1}-T_{\text {wall }, i-1}\right)-\frac{V_{i-1}}{\Delta t} P_{\text {cond }}^{0}+\frac{V_{i-1} \rho_{i-1}}{\Delta t} h_{i-1}^{0} \\
-\alpha_{i} \frac{A_{i}}{N_{\text {cells }}}\left(T_{i}-T_{\text {wall, } i}\right)-\frac{V_{i}}{\Delta t} P_{\text {cond }}^{0}+\frac{V_{i} \rho_{i}}{\Delta t} h_{i}^{0} \\
-\left(m_{\text {cond,ref }}\right)_{\text {out }} h_{\text {cond,out }}-\alpha_{i+1} \frac{A_{i+1}}{N_{\text {cells }}}\left(T_{i+1}-T_{\text {wall }, i+1}\right)-\frac{V_{i+1}}{\Delta t} P_{\text {cond }}^{0}+\frac{V_{i+1} \rho_{i+1}}{\Delta t} h_{i+1}^{0}
\end{array}\right]
\end{aligned}
$$

Equation (18) could be extended to $n$ control volumes as follows: 


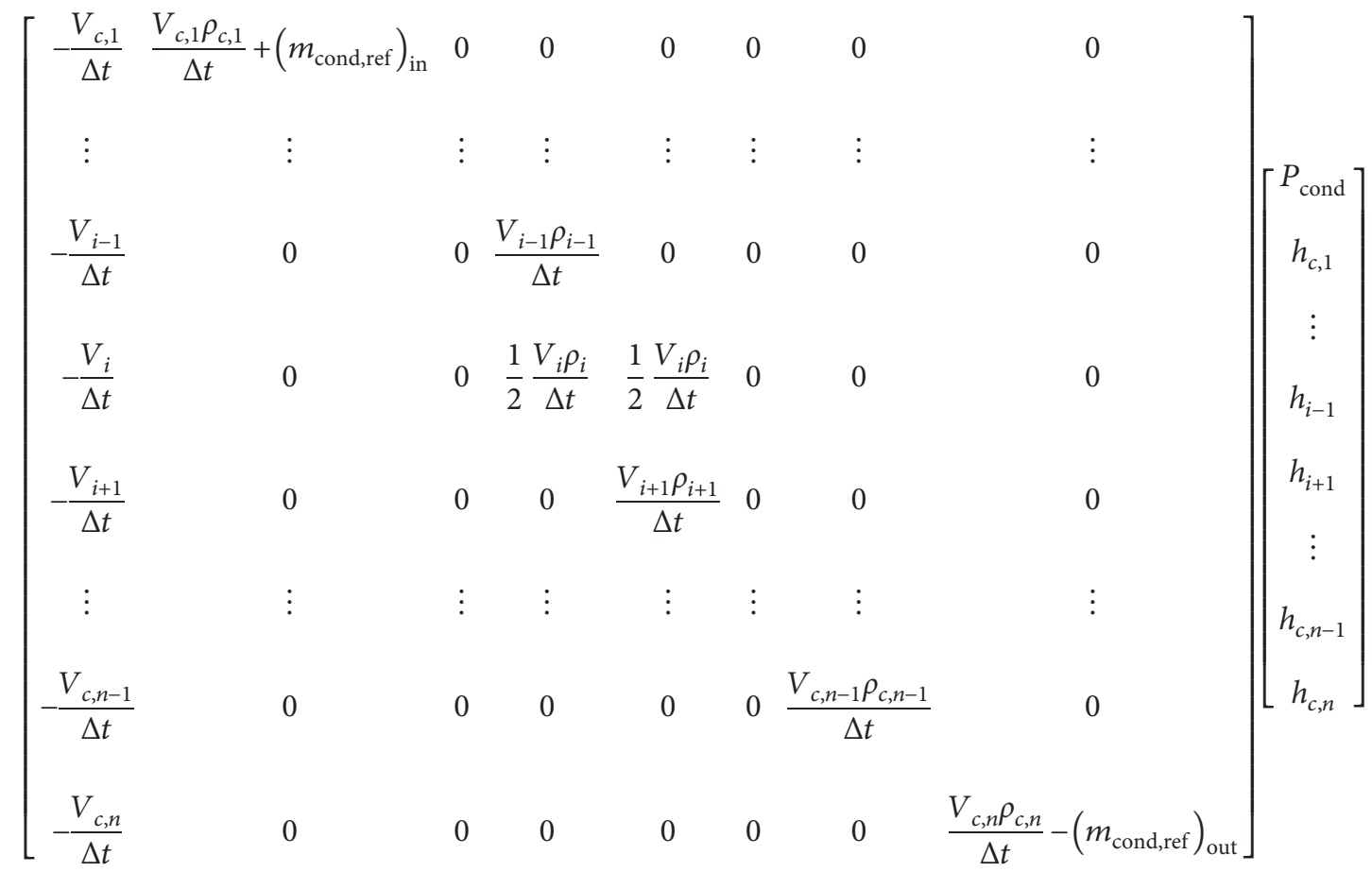

$$
\begin{aligned}
& {\left[\begin{array}{c}
\left(m_{\text {cond,ref }}\right)_{\text {in }} h_{\text {cond,in }}-\alpha_{c, 1} \frac{A_{c, 1}}{N_{\text {cells }}}\left(T_{c, 1}-T_{\text {wall }, c, 1}\right)-\frac{V_{c, 1}}{\Delta t} P_{\text {cond }}^{0}+\frac{V_{c, 1} \rho_{c, 1}}{\Delta t} h_{c, 1}^{0} \\
\vdots \\
-\alpha_{i-1} \frac{A_{i-1}}{N_{\text {cells }}}\left(T_{i-1}-T_{\text {wall }, i-1}\right)-\frac{V_{i-1}}{\Delta t} P_{\text {cond }}^{0}+\frac{V_{i-1} \rho_{i-1}}{\Delta t} h_{i-1}^{0} \\
-\alpha_{i} \frac{A_{i}}{N_{\text {cells }}}\left(T_{i}-T_{\text {wall }, i}\right)-\frac{V_{i}}{\Delta t} P_{\text {cond }}^{0}+\frac{V_{i} \rho_{i}}{\Delta t} h_{i}^{0} \\
-\alpha_{i+1} \frac{A_{i+1}}{N_{\text {cells }}}\left(T_{i+1}-T_{\text {wall }, i+1}\right)-\frac{V_{i+1}}{\Delta t} P_{\text {cond }}^{0}+\frac{V_{i+1} \rho_{i+1}}{\Delta t} h_{i+1}^{0} \\
\vdots \\
-\alpha_{c, n-1} \frac{A_{c, n-1}}{N_{\text {cells }}}\left(T_{c, n-1}-T_{\text {wall }, c, n-1}\right)-\frac{V_{c, n-1}}{\Delta t} P_{\text {cond }}^{0}+\frac{V_{c, n-1} \rho_{c, n-1} h_{c, n-1}^{0}}{\Delta t} \\
-\left(m_{\text {cond,ref }}\right)_{\text {out }} h_{\text {cond,out }}-\alpha_{c, n} \frac{A_{c, n}}{N_{\text {cells }}}\left(T_{c, n}-T_{\text {wall }, c, n}\right)-\frac{V_{c, n}}{\Delta t} P_{\text {cond }}^{0}+\frac{V_{c, n} \rho_{c, n}}{\Delta t} h_{c, n}^{0}
\end{array}\right]}
\end{aligned}
$$

The wall temperature within any control volume of the condenser model could be defined as follows: 


$$
\begin{aligned}
\left(T_{\text {wall }, k}\right)_{\text {cond }}= & \frac{\alpha_{k} A_{k}}{\alpha_{k} A_{k}+A_{\text {cond,eff }} U_{\text {cond,water }}+\left((\mathrm{MC})_{\text {cond }} / \Delta t\right)}\left(T_{k}\right)_{\text {cond }} \\
& +\frac{A_{\text {cond,eff }} U_{\text {cond,water }}}{\alpha_{k} A_{k}+A_{\text {cond,eff }} U_{\text {cond,water }}+\left((\mathrm{MC})_{\text {cond }} / \Delta t\right)}\left(T_{\text {water,in }}\right)_{\text {cond }}+\frac{\left((\mathrm{MC})_{\text {cond }} / \Delta t\right)}{\alpha_{k} A_{k}+A_{\text {cond,eff }} U_{\text {cond,water }}+\left((\mathrm{MC})_{\text {cond }} / \Delta t\right)}\left(T_{\text {wall, } k}^{0}\right)_{\text {cond' }}
\end{aligned}
$$

where $k$ represents the number of control volume and is defined as follows:

$$
k=\{1 ; 2 ; \ldots, \ldots, \ldots ; n-1 ; n\} .
$$

\section{Experimental Investigation of a VC System}

The experimental setup is formed by the 4 main components of a conventional VC system. The compressor consists of a reciprocating piston electrically driven by a 3-phase inverter motor.

The condenser and evaporator units consist of plate heat exchangers using recirculated water at room temperature as secondary fluid. The expansion device consists of a thermostatic expansion valve.

The refrigerant temperature is measured at the outlet of the thermostatic valve by an expansion valve thermocouple and at the outlet of the evaporator coil by a temperaturesensing bulb. Two electronics pressure transducers are installed at the inlet and outlet of the compressor to measure the refrigerant pressure on the low- and high-pressure sides of the compressor.

The data acquisition system is the RA1 software, and data logger is run by a Windows personal computer (PC). The software enables real-time control, and monitoring of all the measurement device outputs with a mimic diagram displayed on the PC screen.

\section{Results and Discussion}

In Figure 3, vapor refrigerant R134a enters the compressor to undergo compression with its temperature rising above saturation (superheating) prior to exiting. High temperature refrigerant enters the condenser for superheat removal so that phase change from vapor to liquid could occur through latent heat removal at constant temperature and pressure. Liquid refrigerant exits the condenser and the heat removed is carried by surrounding water.

Liquid refrigerant enters the expansion valve to undergo expansion with abrupt pressure drop prior to exiting under low temperature and pressure liquid-vapor mixture. Low temperature refrigerant mixture enters the evaporator to be heated by surrounding water so that phase change to vapor could occur prior to returning to the compressor. The actual image of the experimental setup given in Figures 4 and 5 describes the refrigerant's thermodynamic cycle in $\mathrm{VC}$ systems.

Figure 6 presents the variation of the refrigerant density with time within the condenser, whilst Figure 7 presents a similar distribution within the evaporator. Variation of refrigerant temperature with time within the condenser is represented in Figure 8, whilst its counterpart in the evaporator is represented in Figure 9.

The model validation with experiment of the transient distribution of the refrigerant enthalpy within the condenser and evaporator is, respectively, represented in Figures 10 and 11. It is important to remind that the thermal behavior of the evaporator is similar to one of the condensers but on the reverse side; thus, its modelling equations have not been presented in this work. The model validation with the experiments of the transient distribution of the condensing and evaporating pressures is presented in Figure 12.

The experimental setup reached steady conditions after running for approximately 10 minutes with the water flow rate set at $50 \%$ of full range through the condenser and at $70 \%$ of full range through the evaporator.

Compressor and expansion valve are treated as a static model. The inputs are provided by the conditions calculated from the condenser and evaporator models. Outlet enthalpy and mass flow rate within the compressor and expansion valve are determined by using equations (1)(3).

The condenser model is developed under the assumption that the refrigerant is circulating through a thin, long, uniform, circular, and horizontal tube. Conduction effects within the axial direction of the tube are negligible and the refrigerant is flowing following a longitudinal trajectory.

Pressure and enthalpy values determined for a foregoing time step were used as initial values for the ensuing time step considering the fact that between two consecutive time steps the change in refrigerant conditions could be very small. Pressure drop is neglected since viscous forces and momentum on the refrigerant are negligible; therefore, the condenser and evaporator models are isobaric. The latter condition is sufficient to describe with accuracy the transient states of the condenser model [13].

Data were recorded every second for each time step. The average value of each range of data was plotted against their respective time step. The refrigerant density along the condenser model (Figure 6) and evaporator model (Figure 7) remained unchanged with time and this was probably due to short time delay of data recording. The inlet refrigerant enthalpy at the condenser was higher than its outlet counterpart because the refrigerant stores more energy in the gaseous phase. The outlet refrigerant enthalpy at the evaporator was higher than its inlet counterpart as the 


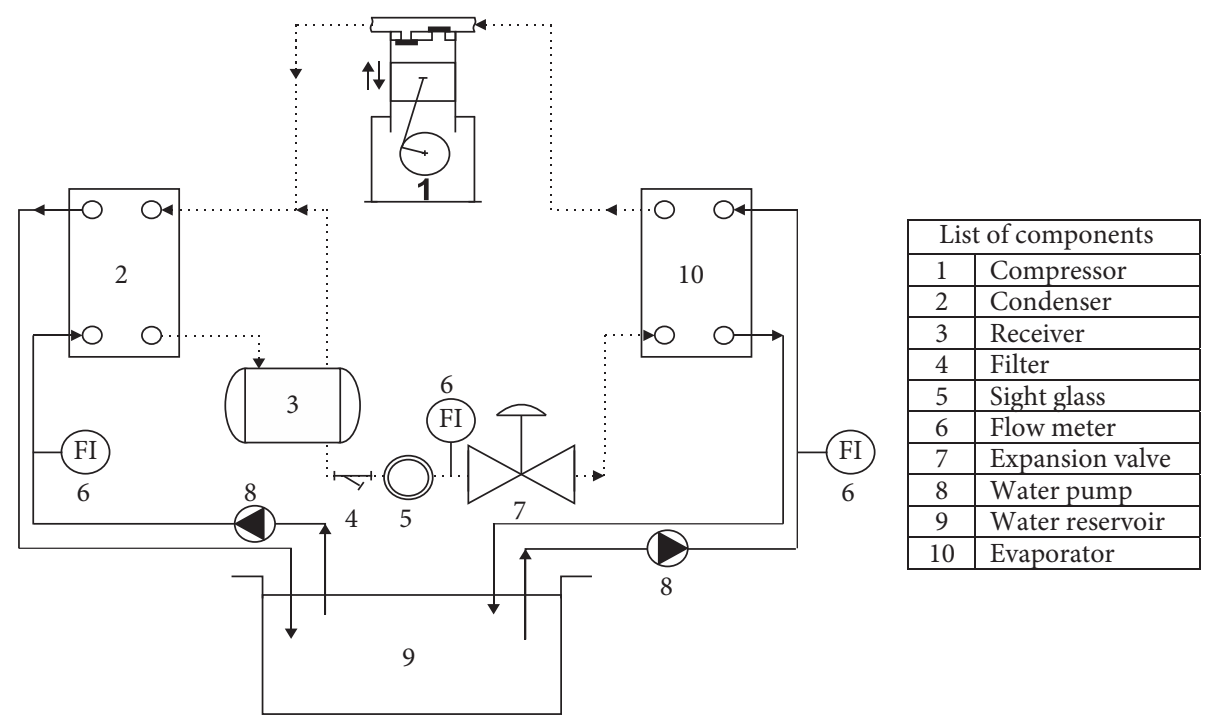

FIgURE 3: Experimental setup.

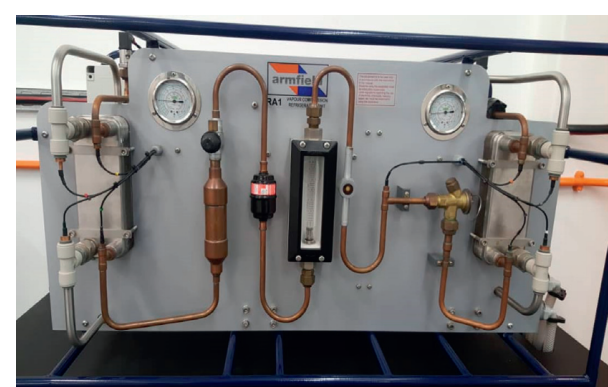

Figure 4: Experimental setup image [26].

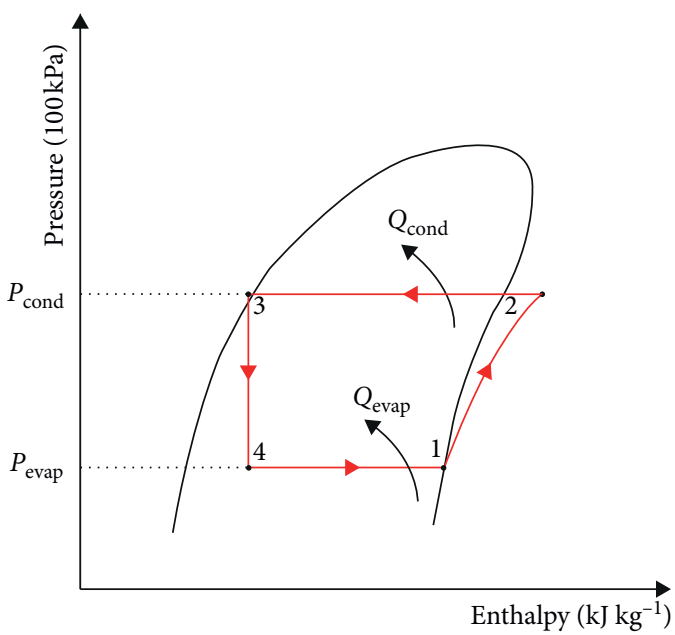

Figure 5: $\mathrm{p}$-h diagram of the experimental setup.

refrigerant enters the evaporator fully liquid and exits fully gaseous. The refrigerant temperature at the condenser inlet and outlet were identical for about $5 \mathrm{~min}$ (Figure 8); then, the outlet temperature dropped significantly due to heat removal to surrounding water stream, whilst the inlet

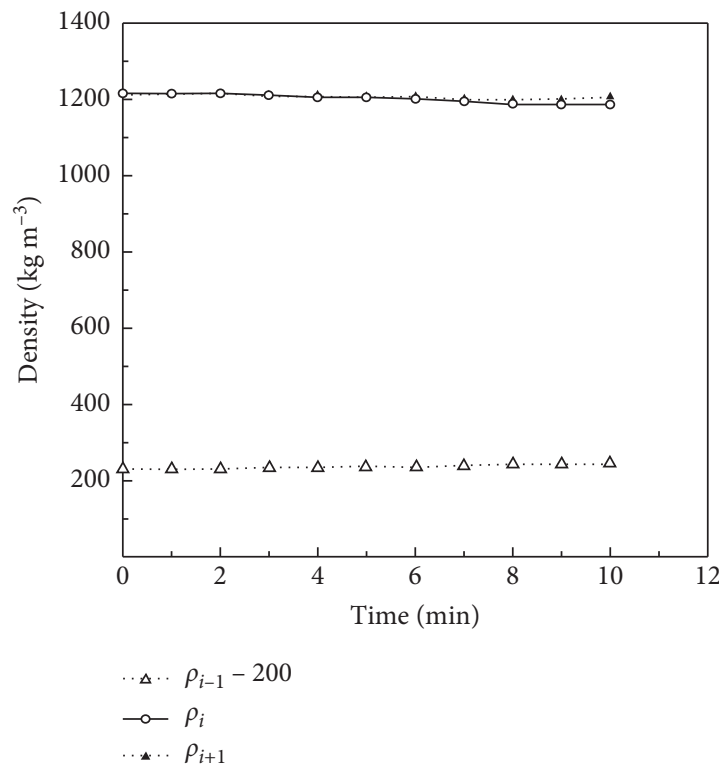

FIgURE 6: Refrigerant density in the condenser.

temperature rose due to increasing high pressure and temperature gas at the compressor outlet. The inlet and outlet refrigerant temperatures in the evaporator remained identical for about $3 \mathrm{~min}$ (Figure 9); then, the inlet temperature significantly dropped compared to the outlet temperature so that more heat from surrounding water stream could be absorbed as the refrigerant circulated through the evaporator. The curve trends of the refrigerant conditions through the condenser and evaporator confirmed that the experiment's outputs are satisfactory for accurate predictions.

Prediction across the condenser was performed by coding equation (19) in Matlab for outputs' tracking with Gaussian elimination for every time step of 60 seconds. Initial conditions for pressure and enthalpies were specified 


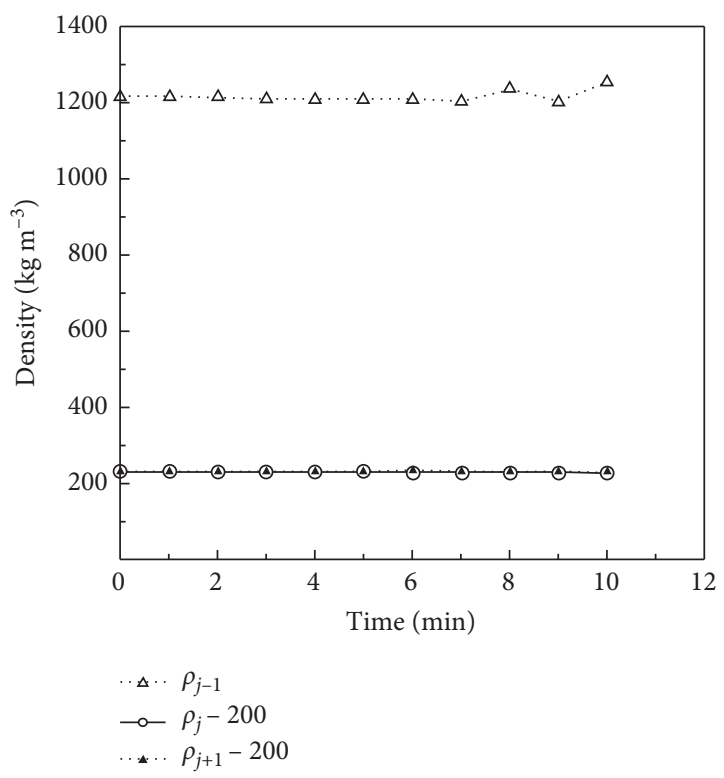

FIgURE 7: Refrigerant density in the evaporator.

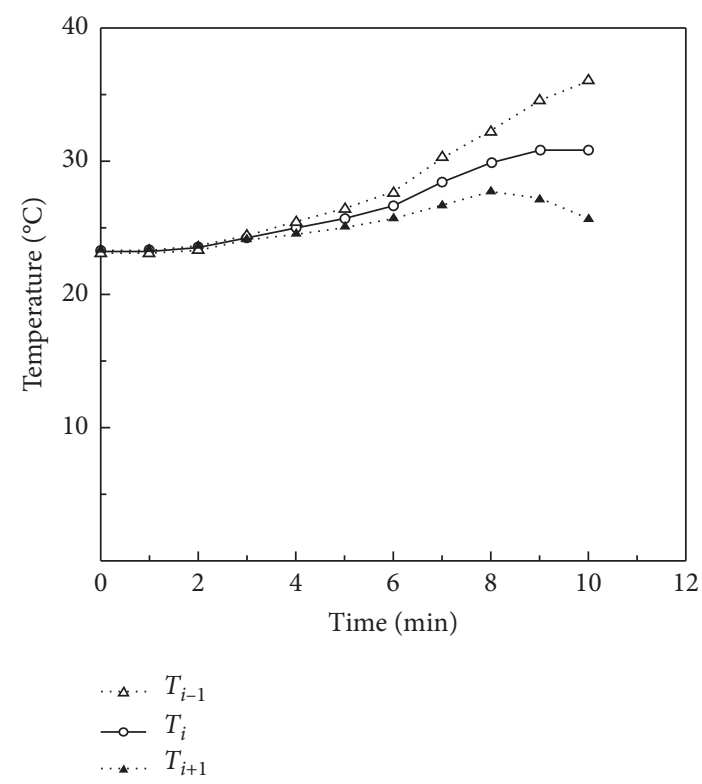

FIgURE 8: Refrigerant temperature in the condenser.

in Table 1 for the models. Matlab results were validated with experiments. Finite volume formulation requires to divide the condenser model into a number of control volumes of the same size in which the refrigerant conditions may change and heat transfer coefficient (HTC) should be evaluated as the fluid undergoes phase change through superheating, two-phase, and subcooling regions. Fluid properties such as refrigerant and water's specific heat capacity are determined from property tables. Superheating and subcooling HTC's are determined with the correlation of [27], whilst two-phase HTC is determined with the correlation of [28]. On the contrary, HTC of water stream is determined with Colburn J-factor.

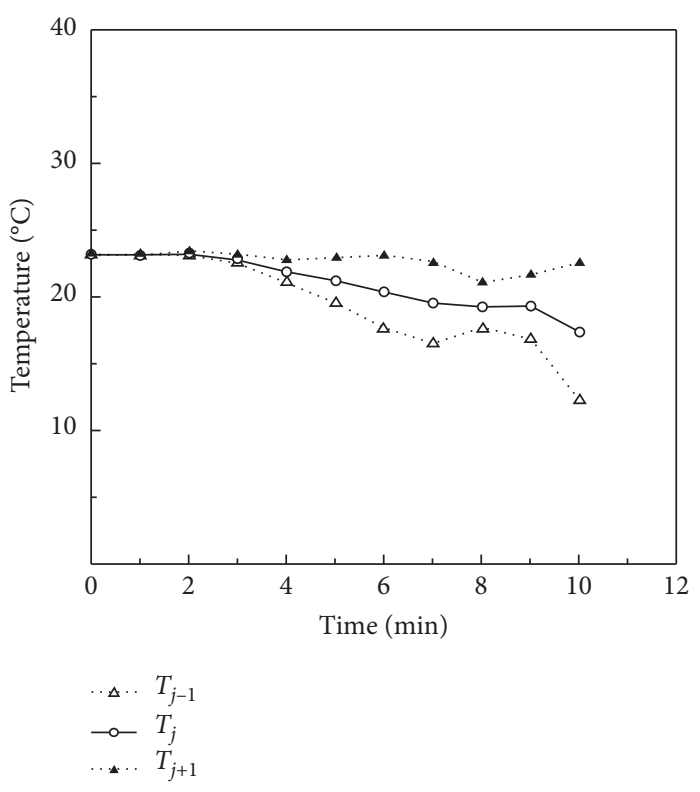

FIGURE 9: Refrigerant temperature in the evaporator.

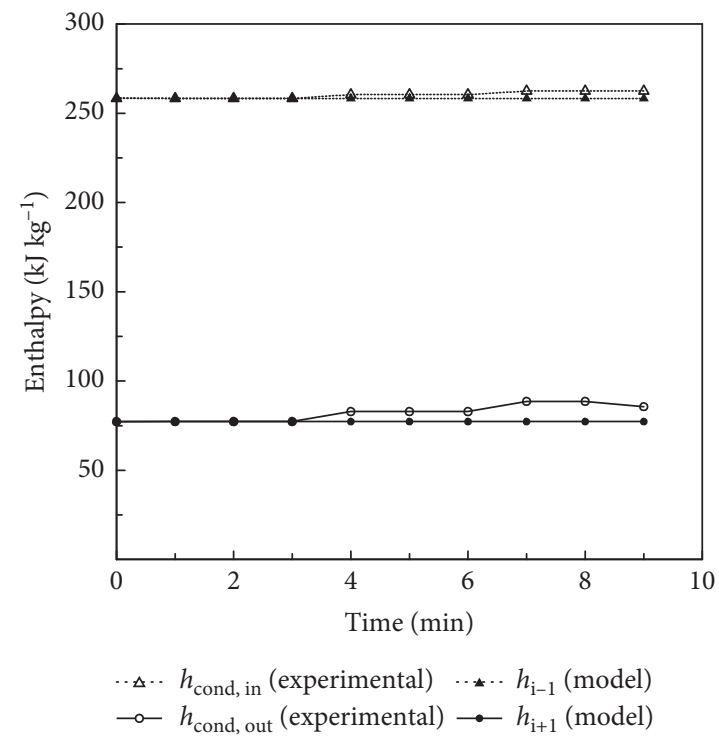

FIGURE 10: Refrigerant enthalpy in the condenser.

Discontinued correlations and interpolated parameters from property tables created numerical issues at times and were, therefore, treated with caution. For instance, issues occurred in computing HTC within the condenser as it was calculated within each control volume whilst varying with enthalpy, pressure, and flow rate at each time step. The numerical issues slowed the model solution tracking, but this was solved with smooth integrated function uplifting discontinuity due to correlations and interpolated parameters. Intermediate mass flow rates and enthalpies within the condenser were cancelled out algebraically. The lumped mass flow rate was determined from equation (19) and used for correlation of HTC within each control volume. Lumped enthalpies and pressure distributions were also computed 


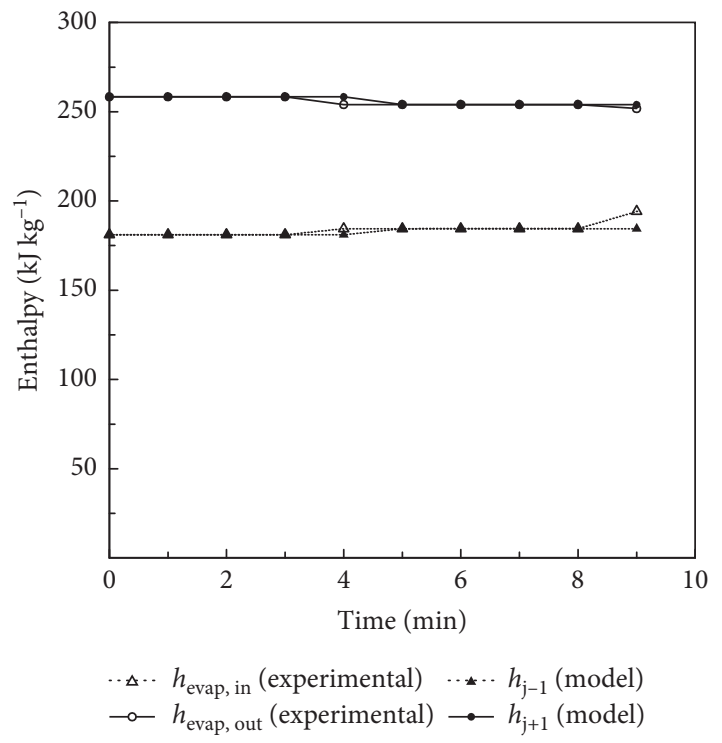

FIGURE 11: Refrigerant enthalpy in the evaporator.

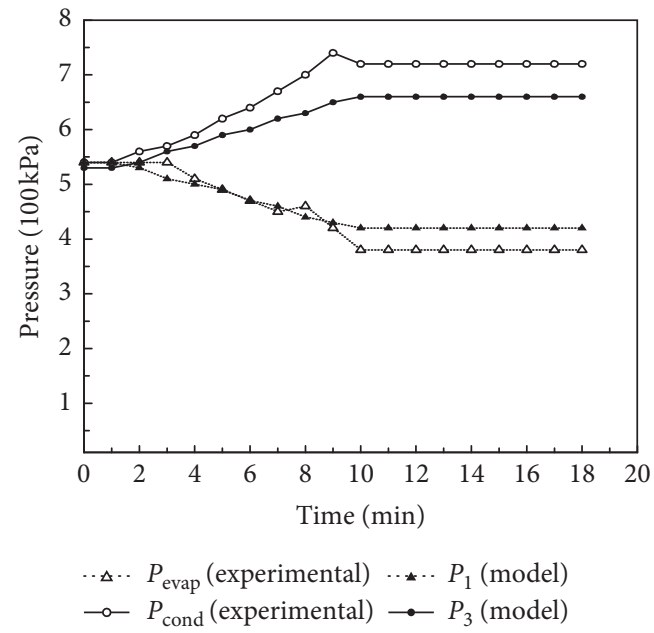

Figure 12: Refrigerant pressure in the condenser and the evaporator.

TABle 1: Transient state parameters.

Parameters

Condenser

Evaporator

$V_{i-1}=V_{i}=V_{i+1}=0.008 \mathrm{~m}^{3}$

$A_{i-1}=A_{i}=A_{i+1}=0.02 \mathrm{~m}^{2}$

$A_{i-1}=A_{i}=A_{i+1}$
$P_{\text {cond }}^{0}=540 \mathrm{kP}_{a}$

$h_{i-1}^{0}=h_{\text {cond,in }}=258.4 \mathrm{kJkg}^{-1}$

$h_{i}^{0}=167.8 \mathrm{kJkg}^{-1}$

$h_{i+1}^{0}=h_{\text {cond,out }}=77.3 \mathrm{kJkg}^{-1}$

$\left(m_{\text {cond,ref }}\right)_{\text {in }}=\left(m_{\text {cond,ref }}\right)_{\text {out }}=0.01 \mathrm{kgs}^{-1}$

$$
\begin{gathered}
V_{j-1}=V_{j}=V_{j+1}=0.008 \mathrm{~m}^{3} \\
A_{j-1}=A_{j}=A_{j+1}=0.02 \mathrm{~m}^{2} \\
P_{\text {evap }}^{0}=540 \mathrm{kP}_{a} \\
h_{j-1}^{0}=h_{\text {evap,in }}=181.1 \mathrm{kJkg}^{-1} \\
h_{j}^{0}=219.7 \mathrm{kJkg}^{-1} \\
h_{j+1}^{0}=h_{\text {evap,out }}=258.4 \mathrm{kJkg}^{-1}
\end{gathered}
$$

$\left(m_{\text {evap,ref }}\right)_{\text {in }}=\left(m_{\text {evap,ref }}\right)_{\text {out }}=0.01 \mathrm{kgs}^{-1}$ from equation (19). Assuming linear enthalpy distribution, lumped enthalpy at the central node was computed from interpolation of lumped enthalpies of surrounding nodes.

Predicted refrigerant enthalpy at the evaporator outlet was in agreement with experiments (Figure 11) with an average value of $256 \mathrm{kJkg}^{-1}$ and slightly lower than the refrigerant enthalpy of $258 \mathrm{kJkg}^{-1}$ (Figure 10) at the condenser inlet. Predicted refrigerant enthalpy at the condenser outlet was in agreement with experiments with an average of $77 \mathrm{kJkg}^{-1}$ (Figure 10) and confirmed that downstream 
condenser heat is removed from the refrigerant by the surrounding water stream. Refrigerant enthalpy through the evaporator inlet was at an average of $190 \mathrm{kJkg}^{-1}$ (Figure 11) and in agreement with experiments.

Predicted evaporating pressure was in agreement with experiments (Figure 12). This pressure was determined with outputs' reduction of $15 \mathrm{kPa}$ at every time step to avoid flat pressure change. Expansion device-evaporator's junction and evaporator-compressor's junction had the same lowest pressure. These junctions could be referred to as system's low-pressure side (Figure 1). The condensing pressure was also determined with outputs' increment of $15 \mathrm{kPa}$ at every time step to avoid flat pressure change. Predicted condensing pressure was in agreement with experiments (Figure 12). The compressor-condenser's junction and condenser-expansion device's junction had the same highest pressure. These junctions could be referred to as system's high-pressure side (Figure 1).

\section{Conclusion}

A transient modelling technique for the $\mathrm{VC}$ system was developed using existing modelling equations. The condenser and the evaporator were divided in small control volumes in order to discretize the PDE's. The finite volume scheme was used to discretize the spatial terms of PDE's across the heat exchanger models, whilst time derivatives' terms were approximated with initial and final values. The finite volume scheme was adopted due to its flexibility to adapt to different system's configuration, as its discretization method is simple, and for its ability to evaluate systems' dynamic behavior. Despite slow solution tracking, the scheme is more accurate when highly discretized. Discretization was performed around nodal points of each control volume to obtain a system of algebraic equations for solution tracking. Some parameters were set in order to solve the system of equations and the outputs of the previous time step were used as inputs for the following time step.

Experimental data were confirmed relevant for model validation. Predicted evaporating and condensing pressures were in good agreement with experiments. Predicted junction enthalpies also converged with experiments. Condensing and evaporating pressures, respectively, increased and decreased with time before reaching the steady state. The transient state was caused by existing pressure gradient in the condenser and evaporator. Other parameters such as density and enthalpy did not significantly change with time. The results could be used to determine optimal system's parameters required to implement optimal controllers. However, improvement could be made by considering a transient mass flow rate within the expansion valve and the compressor during start-up operation instead of adopting a quasi-static approach. The heat transfer coefficients within the heat exchangers could also be evaluated with more accuracy by taking into account the refrigerant phase change and one could attempt to evaluate pressure drop within the condenser and evaporator models.

\section{Nomenclature}

List of symbols

$h_{\text {comp,out }} \quad$ Refrigerant enthalpy at the compressor outlet $\left(\mathrm{kJkg}^{-1}\right)$

$h_{\text {comp,in }} \quad$ Refrigerant enthalpy at the compressor inlet $\left(\mathrm{kJkg}^{-1}\right)$

$h_{\text {isen,out }}$ : Refrigerant isentropic enthalpy at the compressor outlet $\left(\mathrm{kJkg}^{-1}\right)$

$s_{\text {comp }}:$

$\eta_{\text {isen }}:$

$m_{\text {comp }}$ :

$\eta_{\text {vol }}:$

$\rho_{\text {comp,in }}:$

$D_{v}:$

Refrigerant entropy in the compressor $\left(\mathrm{kJkg}^{-1} \circ \mathrm{C}^{-1}\right)$

Isentropic efficiency of the compressor

Refrigerant mass flow rate in the compressor $\left(\mathrm{kgs}^{-1}\right)$

Volumetric efficiency of the compressor

Density of refrigerant at the compressor inlet $\left(\mathrm{kgm}^{-3}\right)$

Displacement volume of the compressor $\left(\mathrm{m}^{3} \mathrm{~s}^{-1}\right)$

$\mathrm{RPM}_{\text {comp }}$ : Rotational speed of the compressor ( $\left.\mathrm{rpm}\right)$

$(\mathrm{MC})_{\text {cond }}$ : Thermal mass of the condenser wall $\left(\mathrm{kJ}^{\circ} \mathrm{C}^{-1}\right)$

$Q_{\text {water }, i}$ : Heat absorbed by water in the condenser (kW)

$Q_{\text {cond }}$ :

$U_{\text {cond,water: }}$

$A_{\text {cond,eff }}$ :

$A_{\text {cond,tube }}$

$\eta_{\text {cond,fin }}$ :

$A_{\text {cond,fin }}$ :

$l_{\text {cond }}$ :

$d_{\text {cond }}$ :

$m_{t x v}$ :

$C_{t x v}$ :

$T_{\text {Sh,operating }}$ :

$T_{\text {Sh,static }}$ :

$\rho_{t x v, \text { in }}$ :

Heat rejection in the condenser $(\mathrm{kw})$

Heat transfer coefficient of water in the condenser $\left(\mathrm{kwm}^{-2} \circ \mathrm{C}^{-1}\right)$

Effective outer surface of the condenser $\left(\mathrm{m}^{2}\right)$

Outer surface of condenser tubes $\left(\mathrm{m}^{2}\right)$

Effectiveness of condenser fins

Surface of condenser fins $\left(\mathrm{m}^{2}\right)$

Condenser length $(\mathrm{m})$

Inner diameter of the condenser (m)

Refrigerant mass flow rate in the expansion valve $\left(\mathrm{kgs}^{-1}\right)$

Valve flow coefficient

Refrigerant operating superheat $\left({ }^{\circ} \mathrm{C}\right)$

Refrigerant static superheat $\left({ }^{\circ} \mathrm{C}\right)$

Refrigerant density at the expansion valve inlet $\left(\mathrm{kgm}^{-3}\right)$

$P_{t x v, \text { in }}: \quad$ Refrigerant pressure at the expansion valve inlet $\left(\mathrm{kP}_{a}\right)$

$P_{t x v, \text { out }}: \quad$ Refrigerant pressure at the expansion valve outlet $\left(\mathrm{kP}_{a}\right)$

$h_{t x v \text {,out }}$ : $\quad$ Refrigerant enthalpy at the expansion valve outlet $\left(\mathrm{kJkg}^{-1}\right)$

$P_{1}$ : Junction pressure at the evaporator outlet $\left(\mathrm{kP}_{a}\right)$

$P_{2}$ : $\quad$ Junction pressure at the condenser inlet $\left(\mathrm{kP}_{a}\right)$

$P_{3}$ : $\quad$ Junction pressure at the condenser outlet $\left(\mathrm{kP}_{a}\right)$

$P_{4}$ : Junction pressure at the evaporator inlet $\left(\mathrm{kP}_{a}\right)$ 


\begin{tabular}{|c|c|}
\hline$V_{i}:$ & Internal volume of $i^{\text {th }}$ control volume $\left(\mathrm{m}^{3}\right)$ \\
\hline$h_{i}:$ & $\begin{array}{l}\text { Refrigerant enthalpy in } i^{\text {th }} \text { control volume } \\
\left(\mathrm{kJkg}^{-1}\right)\end{array}$ \\
\hline$\left(m_{\text {cond,ref }}\right)_{\text {in }}:$ & $\begin{array}{l}\text { Refrigerant mass flow rate at the condenser } \\
\text { inlet }\left(\mathrm{kgs}^{-1}\right)\end{array}$ \\
\hline$\left(m_{\text {cond,ref }}\right)_{\text {out }}:$ & $\begin{array}{l}\text { Refrigerant mass flow rate at the condenser } \\
\text { outlet }\left(\mathrm{kgs}^{-1}\right)\end{array}$ \\
\hline$h_{\text {cond,in }}:$ & $\begin{array}{l}\text { Refrigerant enthalpy at the condenser inlet } \\
\left(\mathrm{kJkg}^{-1}\right)\end{array}$ \\
\hline$h_{\text {cond,out }}:$ & $\begin{array}{l}\text { Refrigerant enthalpy at the condenser outlet } \\
\left(\mathrm{kJkg}^{-1}\right)\end{array}$ \\
\hline$Q_{\mathrm{ref}, i}:$ & $\begin{array}{l}\text { Heat rejected by refrigerant in the condenser } \\
(\mathrm{kw})\end{array}$ \\
\hline$P_{\text {cond }}^{0}:$ & $\begin{array}{l}\text { Initial refrigerant pressure in the condenser } \\
\left(\mathrm{kP}_{a}\right)\end{array}$ \\
\hline$h_{i}^{0}:$ & $\begin{array}{l}\text { Initial refrigerant enthalpy in } i^{\text {th }} \text { control } \\
\text { volume of the condenser }\left(\mathrm{kJkg}^{-1}\right)\end{array}$ \\
\hline$\Delta t:$ & Time step $(s)$ \\
\hline$t:$ & Final time $(s)$ \\
\hline$t^{0}:$ & Initial time $(s)$ \\
\hline$V_{c, n}:$ & $\begin{array}{l}\text { Internal volume of } n^{\text {th }} \text { control volume in the } \\
\text { condenser }\left(\mathrm{m}^{3}\right)\end{array}$ \\
\hline$\rho_{c, n}:$ & $\begin{array}{l}\text { Refrigerant density in } n^{\text {th }} \text { control volume of } \\
\text { the condenser }\left(\mathrm{kgm}^{-3}\right)\end{array}$ \\
\hline$h_{c, n}:$ & $\begin{array}{l}\text { Refrigerant enthalpy in } n^{\text {th }} \text { control volume of } \\
\text { the condenser }\left(\mathrm{kJkg}^{-1}\right)\end{array}$ \\
\hline$\alpha_{c, n}:$ & $\begin{array}{l}\text { Heat transfer coefficient in } n^{\text {th }} \text { control volume } \\
\text { of the condenser }\left(\mathrm{kwm}^{-2}{ }^{\circ} \mathrm{C}^{-1}\right)\end{array}$ \\
\hline$A_{c, n}:$ & $\begin{array}{l}\text { Internal surface of } n^{\text {th }} \text { control volume in the } \\
\text { condenser }\left(\mathrm{m}^{2}\right)\end{array}$ \\
\hline$T_{c, n}:$ & $\begin{array}{l}\text { Refrigerant temperature in } n^{\text {th }} \text { control } \\
\text { volume of the condenser }\left({ }^{\circ} \mathrm{C}\right)\end{array}$ \\
\hline$T_{\text {wall }, c, n}:$ & $\begin{array}{l}\text { Wall temperature in } n^{\text {th }} \text { control volume of the } \\
\text { condenser }\left({ }^{\circ} \mathrm{C}\right)\end{array}$ \\
\hline$h_{c, n}^{0}:$ & $\begin{array}{l}\text { Initial refrigerant enthalpy in } n^{\text {th }} \text { control } \\
\text { volume of the condenser }\left(\mathrm{kJkg}^{-1}\right)\end{array}$ \\
\hline$\left(T_{\text {wall }, k}\right)_{\text {cond }}:$ & $\begin{array}{l}\text { Wall temperature in } k^{\text {th }} \text { control volume of the } \\
\text { condenser }\left({ }^{\circ} \mathrm{C}\right)\end{array}$ \\
\hline$\left(T_{k}\right)_{\text {cond }}:$ & $\begin{array}{l}\text { Refrigerant temperature in } k^{\text {th }} \text { control } \\
\text { volume of the condenser }\left({ }^{\circ} \mathrm{C}\right)\end{array}$ \\
\hline$\left(T_{\text {wall }, k}^{0}\right)_{\text {cond }}:$ & $\begin{array}{l}\text { Initial wall temperature in } k^{\text {th }} \text { control volume } \\
\text { of the condenser }\left({ }^{\circ} \mathrm{C}\right)\end{array}$ \\
\hline$P_{\text {evap }}:$ & Refrigerant pressure in the evaporator $\left(\mathrm{kP}_{a}\right)$ \\
\hline$P_{\text {evap }}^{0}:$ & $\begin{array}{l}\text { Initial refrigerant pressure in the evaporator } \\
\left(\mathrm{kP}_{a}\right)\end{array}$ \\
\hline$Q_{\text {evap: }}:$ & Heat absorption in evaporator $(\mathrm{kw})$. \\
\hline \multicolumn{2}{|l|}{ Greek symbols } \\
\hline \multicolumn{2}{|l|}{$\eta:$ Efficiency } \\
\hline \multicolumn{2}{|c|}{$\mu:$ Viscosity $\left(\mathrm{kgm}^{-1} \mathrm{~s}^{-1}\right)$} \\
\hline \multicolumn{2}{|c|}{$\rho:$ Density $\left(\mathrm{kgm}^{-3}\right)$} \\
\hline \multicolumn{2}{|c|}{$\alpha$ : Heat transfer coefficient $\left(\mathrm{kwm}^{-2}{ }^{\circ} \mathrm{C}^{-1}\right)$} \\
\hline \multicolumn{2}{|l|}{ Superscripts } \\
\hline \multicolumn{2}{|c|}{0 : Initial condition. } \\
\hline \multicolumn{2}{|l|}{ Subscripts } \\
\hline comp, out: & Compressor outlet \\
\hline comp, in: & Compressor inlet \\
\hline comp: & Compressor \\
\hline
\end{tabular}

$\begin{array}{ll}\text { isen: } & \text { Isentropic } \\ \text { Vol: } & \text { Volumetric } \\ v: & \text { Volume } \\ \text { cond: } & \text { Condenser } \\ \text { water: } & \text { Water stream } \\ \text { eff: } & \text { Effective } \\ \text { tube: } & \text { Condenser or evaporator tube } \\ \text { fin: } & \text { Condenser or evaporator fin } \\ \text { ref: } & \text { Refrigerant stream } \\ t x v: & \text { Thermostatic expansion valve } \\ \text { Sh, operating: } & \text { Operating superheat } \\ \text { Sh, static: } & \text { Static superheat } \\ t x v, \text { in: } & \text { Thermostatic expansion valve inlet } \\ t x v, \text { out: } & \text { Thermostatic expansion valve outlet } \\ 1: & \text { Junction } 1 \\ 2: & \text { Junction } 2 \\ 3: & \text { Junction } 3 \\ 4: & \text { Junction } 4 \\ i: & i^{\text {th }} \text { control volume } \\ \text { in: } & \text { Inlet } \\ \text { out: } & \text { Outlet } \\ \text { cond, in: } & \text { Condenser inlet } \\ \text { cond, out: } & \text { Condenser outlet } \\ c, n: & n^{\text {th }} \text { control volume of the condenser } \\ \text { wall, } c, n: & \text { Wall of } n^{\text {th }} \text { control volume of the condenser } \\ \text { wall, } k: & \text { Wall of } k^{\text {th }} \text {-control volume of condenser } \\ k: & k^{\text {th }} \text { control volume } \\ \text { evap: } & \text { Evaporator. } \\ & \end{array}$

\section{Data Availability}

The data used to support the findings of the study are included within the article.

\section{Conflicts of Interest}

The authors declare no conflicts of interest.

\section{Acknowledgments}

This work was supported by the Centre of New Energy Systems in the Department of Electrical, Electronic, and Computer Engineering at University of Pretoria, South Africa.

\section{References}

[1] P. Welsby, S. Devotta, and P. J. Diggory, "Steady- and dynamic-state simulations of heat-pumps. Part I: literature review," Applied Energy, vol. 31, no. 3, pp. 189-203, 1988.

[2] G. L. Wedekind, B. L. Bhatt, and B. T. Beck, "A system mean void fraction model for predicting various transient phenomena associated with two-phase evaporating and condensing flows," International Journal of Multiphase Flow, vol. 4, no. 1, pp. 97-114, 1978.

[3] M. Dhar and W. Soedel, "Transient analysis of vapor compression refrigeration systems," in Proceedings of the 15th International Congress of Refrigeration, pp. 1031-1067, Venetia, Italy, September 1979. 
[4] J. Chi and D. A. Didion, "A simulation model of the transient performance of a heat pump," International Journal of Refrigeration, vol. 5, no. 3, pp. 176-184, 1982.

[5] J. W. MacArthur, "Theoretical analysis of the dynamic interactions of vapor compression heat pumps," Energy Conservation Management, vol. 24, no. 1, pp. 49-66, 1984.

[6] J. W. MacArthur, "Transient heat pump behavior: a theoretical investigation," International Journal of Refrigeration, vol. 7, no. 2, pp. 123-132, 1984.

[7] J. W. MacArthur and E. W. Grald, "Prediction of cyclic heat pump performance with a fully distributed model and a comparison with experimental data," ASHRAE Transactions, vol. 93, 1987.

[8] J. Nyers and G. Stoyan, "A dynamical model adequate for controlling the evaporator of a heat pump," International Journal of Refrigeration, vol. 17, no. 2, pp. 101-108, 1994.

[9] M. Willatzen, N. B. O. L. Pettit, and L. Ploug-Sorensen, "A general dynamic simulation model for evaporators and condensers in refrigeration. Part I: moving-boundary formulation of two-phase flows with heat exchange," International Journal of Refrigeration, vol. 21, no. 5, pp. 398-403, 1998.

[10] N. B. O. L. Pettit, M. Willatzen, and L. Ploug-Sorensen, "A general dynamic simulation model for evaporators and condensers in refrigeration. Part II: simulation and control of an evaporator," International Journal of Refrigeration, vol. 21, no. 5, pp. 404-414, 1998.

[11] T. L. McKinley and A. G. Alleyne, "An advanced nonlinear switched heat exchanger model for vapor compression cycles using the moving-boundary method," International Journal of Refrigeration, vol. 31, pp. 1243-1264, 2008.

[12] B. Li and A. G. Alleyne, "A full dynamic model of a HVAC vapor compression interacting with dynamic environment," in Proceedings of the American Control Conference, pp. 3662-3668, St. Louis, MO, USA, June 2009.

[13] W.-J. Zhang, C.-L. Zhang, and G.-L. Ding, "On three forms of momentum equation in transient modeling of residential refrigeration systems," International Journal of Refrigeration, vol. 32, no. 5, pp. 938-944, 2009.

[14] R. Link and C. J. Deschamps, "Numerical modeling of startup and shutdown transients in reciprocating compressors," International Journal of Refrigeration, vol. 34, no. 6, pp. 13981414, 2011.

[15] B. P. Rasmussen, "Dynamic modeling of vapor compression systems - Part I: literature review," HVAC and R Research, vol. 18, pp. 934-955, 2012.

[16] B. P. Rasmussen and B. Shenoy, "Dynamic modeling for vapor compression systems-part II: simulation tutorial," HVAC and R Research, vol. 18, pp. 956-973, 2012.

[17] H. Satyavada and S. Baldi, "A novel modelling approach for condensing boilers based on hybrid dynamical systems," Machines, vol. 4, no. 2, pp. 1-10, 2016.

[18] H. Satyavada and S. Baldi, "Monitoring energy efficiency of condensing boilers via hybrid first-principle modelling and estimation," Energy, vol. 142, pp. 121-129, 2018.

[19] H. Pangborn, Dynamic Modeling, Validation, and Control for Vapor Compression Systems, University of Illinois at Urbana, Champaign, IL, USA, 2015.

[20] H. Pangborn, A. G. Alleyne, and N. Wu, "A comparison between finite volume and switched moving boundary approaches for dynamic vapor compression system modeling," International Journal of Refrigeration, vol. 53, pp. 101-114, 2015.
[21] F. Bagheri, Development of Efficient Air Conditioning and Refrigeration System for Service Vehicles, School of Mechatronic Systems Engineering, Faculty of Applied Science, Simon Fraser University, Vancouver, Canada, 2016.

[22] M. C. Diniz, C. J. L. Hermes, and C. J. Deschamps, "Transient simulation of small-capacity reciprocating compressors in onoff controlled refrigerators," International Journal of Refrigeration, vol. 102, pp. 12-21, 2019.

[23] M. C. Diniz, C. Melo, and C. J. Deschamps, "Experimental performance assessment of a hermetic reciprocating compressor operating in a household refrigerator under on-off cycling conditions," International Journal of Refrigeration, vol. 88 , pp. 587-598, 2018.

[24] C. Sanama, M. Sharifpur, and J. P. Meyer, "Mathematical modeling of orifice downstream flow under flow-accelerated corrosion," Nuclear Engineering and Design, vol. 326, pp. 285-289, 2018.

[25] J. M. Winkler, Development of a Component-Based Simulation Tool for the Steady State and Transient Analysis of Vapor Compression Systems, Faculty of the Graduate School of the University of Maryland, College Park, MD, USA, 2009.

[26] Armfield Ltd., Instruction Manual: RA1 Vapour-Compression Refrigeration Unit, Armfield Ltd., Ringwood, UK, 2009.

[27] V. Gnielinski, "New equations for heat and mass transfer in the turbulent flow in pipes and channels," NASA, Technical Report A, vol. 752, p. 22020, 1975.

[28] M. K. Dobson and J. C. Chato, "Condensation in smooth horizontal tubes," Journal of Heat Transfer, vol. 120, no. 1, pp. 193-213, 1998. 